\title{
Cranberry extract initiates intrinsic apoptosis in HL-60 cells by increasing BAD activity through inhibition of AKT phosphorylation
}

\author{
Rasha A. Mansouri ${ }^{1 *}$ and Susan S. Percival ${ }^{2}$
}

\begin{abstract}
Background: Cranberry has been studied as a potential anticancer agent as it is capable of inducing apoptosis within cancer cells. The aim of this study was to better define the mechanism by which cranberry triggers apoptosis in HL-60 cells.

Methods: The study was carried on cranberry extracts (CB). Anti-apoptotic B-cell lymphoma-2 (BCL-2) and pro-apoptotic BCL-2-associated death promoter death (BAD) proteins in cell lysates were detected through Western blotting techniques. Equivalent protein loading was confirmed through anti-a-tubulin antibody.

Results: The results showed that treatment of $\mathrm{HL}-60$ cells with $\mathrm{CB}$ causes a significant increase in the levels of caspase- 9 and caspases-3/7 and increased mitochondrial outer membrane permeability, leading to the release of cytochrome $C$ and Smac. These apoptotic events were associated with a significant decrease in protein kinase B (AKT) phosphorylation, which caused significant increase in BAD de-phosphorylation and promoted a sequence of events that led to intrinsic apoptosis.

Conclusion: The study findings have described a molecular framework for CB-initiated apoptosis in HL-60 cells and suggested a direction for future in vivo studies investigating the anticancer effect of cranberry.
\end{abstract}

Keywords: Cranberry, HL-60, Apoptosis, Caspases, Protein kinase B (Akt), BCL-2-associated death promoter (BAD)

\section{Background}

Apoptosis is a complex process involving multiple cellular signaling pathways. Two core pathways have been identified in mammalian cells: the extrinsic or death receptor pathway, and the intrinsic or mitochondrial pathway [1-3]. The underlying mechanistic basis for both pathways involves the sequential activation of a group of cysteine proteases called caspases, which can cleave substrates located in different intracellular compartments

\footnotetext{
* Correspondence: amansouri@kau.edu.sa

'Department of Biochemistry, King Abdul Aziz University, Jeddah, Saudi Arabia

Full list of author information is available at the end of the article
}

during apoptosis [4-6]. Caspases involved in apoptosis are broadly categorized into initiators (caspases 2, 8, 9 and 10) and executioners/effectors (caspases 3, 6 and 7). All caspases are produced in cells as catalytically inactive proenzymes. The activation of an executioner caspase is executed by the activation of an initiator caspase. Once the executioner caspase is activated, it initiates the proteolytic degradation of a broad spectrum of cellular targets that ultimately led to cell death [2, 7].

The extrinsic apoptotic pathway is initiated by the binding of extracellular death ligands to cell surface death receptors. Therefore, it is important to regulate cell death for cancer cells to survive during metastasis. 
This binding creates a cascade of events that activate the initiator caspase that is caspase-8, which then cleaves and activates the executioner caspases, caspase- 3 and -7 [8-11]. In contrast, initiation of the intrinsic apoptotic pathway, by events such as DNA damage, growth factor withdrawal, or loss of contact with the extracellular matrix lead to changes in the integrity of the mitochondrial membrane that result in the release of pro-apoptotic proteins such as cytochrome $\mathrm{C}$ and second mitochondriaderived activator of caspases (Smac). These pro-apoptotic proteins mediate the activation of the initiator caspase that is caspase-9, which triggers the committed execution phase of apoptosis [3, 12-14]. A clear and distinct separation of two pathways is possible based on the links between the extrinsic and intrinsic pathways [14].

Cranberry is effective in treating urinary tract infections in vivo and in vitro animals as it works by inhibiting the adhesion of type I and P-fimbriated uropathogens to the uroepithelium, which impair colonization and subsequent infection [15]. Naturally occurring dietary substances have a long history of use in the treatment of cancer. Cranberries are considered to be rich in bioactive compounds and it is ranked among fruits in both antioxidant quality and quantity due to the presence of flavonoids and phenolic acids [16]. In addition, the presence of flavonoids plays a significant role in cancer inhibition. The potential anticancer activity of cranberry was reported for the first time in 1996 [17]. Evidence has emerged since then to support the anticancer properties of cranberry and a variety of possible mechanisms of action have been proposed [16].

It is important to consider the mechanism of apoptosis in cancer as it helps to understand the pathogenesis of the disease and aid in the development of drugs that can target certain apoptotic proteins or pathways. Therefore, induction of apoptosis is considered among the proposed mechanism of anticancer activity. In vitro studies have shown that cranberry triggers apoptosis through the modulation of a number of key proteins in cellular signal transduction pathways [18-21]. However, the exact mechanism that underlies how cranberry regulates and induces the apoptotic process remains unclear. Therefore, the present study aims to define the mechanism by which cranberry extract (CB) triggers apoptosis in HL-60 cells. This specific cell line was used since it is a well-characterized one and the various biochemical steps occurring during apoptosis have been well documented. In addition, it is a classical cell line model that has been used extensively in apoptosis studies.

\section{Methods}

\section{Cranberry extract}

The CB was obtained from Ocean Spray Cranberries, Inc. (Lakeville, MA, USA). It was derived from the juice portion of the berry and contained $60-65 \%$ proanthocyanidins
(PAC), 9\% flavonols, 6\% anthocyanidins, and 5\% phenolic acids. The composition of $15 \%$ is unknown, but is likely to be sugars, organic acids, and terpenes. For all experiments, $\mathrm{CB}$ was dissolved in DMSO, which was used at a final concentration of $<0.1 \%$ in cell cultures.

\section{Cell culture}

HL-60 cells (CCL-240) were obtained from the American Type Culture Collection (Manassas, VA, USA). These cells were cultured in RPMI 1640 complete medium containing 10\% FBS, 2\% HEPES, $0.1 \%$ gentamicin sulfate, $100 \mathrm{U} / \mathrm{ml}$ penicillin, $100 \mu \mathrm{g} / \mathrm{ml}$ streptomycin, and $0.25 \mu \mathrm{g} / \mathrm{ml}$ amphotericin $\mathrm{B}$ incubated at $37^{\circ} \mathrm{C}$ in a humidified, $5 \% \mathrm{CO}_{2}$ atmosphere, as recommended.

\section{Dose and time determination}

HL-60 cells $\left(8 \times 10^{5}\right)$ in $25 \mathrm{~cm}^{2}$ flasks were treated with two concentrations of CB (25 or $50 \mu \mathrm{g} / \mathrm{ml}), 0.1 \%$ DMSO or $10 \mu \mathrm{M}$ etoposide (BioVision, Inc., Milpitas, CA, USA), and incubated for $24 \mathrm{~h}$ for dosage determination. Cell samples were assayed using the Apo-ONE ${ }^{\bullet}$ Homegenous Caspase-3/7 Assay (Promega, Madison, WI, USA) by following manufacturer's directions. According to the obtained results, $25 \mu \mathrm{g} / \mathrm{ml} \mathrm{CB}$ was used in time dependent manner for further experiments. For optimal incubation time determination, cells were treated with $25 \mu \mathrm{g} / \mathrm{mL} \mathrm{CB}$ and harvested at 2,24 and $48 \mathrm{~h}$. cells were assayed following the same previous Apo-ONE ${ }^{\oplus}$ Homegenous Caspase-3/7 assay.

\section{Experimental treatment}

HL-60 cells were treated with $25 \mu \mathrm{g} / \mathrm{ml} \mathrm{CB}$ for $24 \mathrm{~h}$. Control cells received either 2 or $10 \mu \mathrm{M}$ etoposide, or $0.1 \%$ DMSO. The positive control for the protein kinase B (AKT) activity assay was $20 \mu \mathrm{M}$ PI3K inhibitor LY294002 (Cell Signaling Technology, Danvers, MA, USA).

\section{ELISA determination of protein levels}

Levels of caspase 8 , caspase 9, cytochrome C, and Smac in lysates of HL-60 cells treated with CB were quantified using commercially available ELISA kits (Abcam, Cambridge, MA, USA). AKT and phosphorylated-AKT (p-AKT) levels were also determined by ELISA (Thermo Fisher Scientific, Waltham, MA, USA), and $\mathrm{p}-\mathrm{AKT}$ values were normalized to total AKT.

\section{Measurement of mitochondrial transmembrane potential} HL-60 cells were treated with CB, collected after $24 \mathrm{~h}$, and processed using a Mitochondrial Transmembrane Potential Apoptosis Detection Kit (Abcam). Labeled cells were observed on an EVOS XL microscope (Thermo Fisher Scientific, AMG), using a band-pass filter to detect fluorescein and rhodamine. 


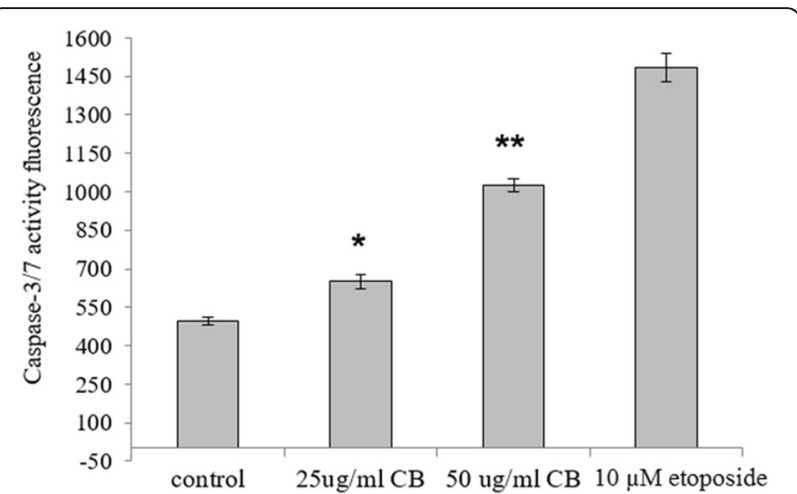

Fig. 1 Change in caspase-3/7 activity after 24-h incubation with different concentration of CB (25 and $50 \mu \mathrm{g} / \mathrm{mL}$ ) and etoposide $(10 \mu \mathrm{M})$. DMSO (0.1\%)-treated cells served as controls. The data represent the mean of three independent experiments \pm SD Statistical analysis were performed by one-way variance analysis (ANOVA) followed by Bonferroni's test. Statistical difference shown as $P<0.05\left[{ }^{*}\right]$

\section{Western blot analysis}

Western blotting techniques were used to detect antiapoptotic B-cell lymphoma-2 (BCL-2) and pro-apoptotic BAD proteins in cell lysates. Briefly, CB-treated HL-60 cells were washed with ice cold PBS and lysed with RIPA buffer containing protease and phosphatase inhibitors. Samples were kept on ice and vortexed occasionally for $30 \mathrm{~min}$. Protein concentrations were determined using a Bio-Rad Protein Assay. Samples were electrophoresed in $12 \%$ SDS-PAGE gels, transferred to nitrocellulose membranes, blocked with 5\% BSA in TBST buffer, and exposed to rabbit monoclonal antibodies at $4{ }^{\circ} \mathrm{C}$ overnight. Blots were probed with HRP-conjugated antirabbit IgG for $1 \mathrm{~h}$ and visualized using superSignal West Pico Chemiluminescent Substrate (Thermo Fisher Scientific). Antibodies to proteins BAD [No.9239], pBAD (Ser112) [No.5284], p-BAD (Ser136) [No.4366], pBAD (Ser155) [No.9297], BCL-2 [No.2870], p-BCL-2
(Ser70) [No.2827], and anti-rabbit IgG-HRP [No.7074] were purchased from Cell Signaling Technology. Anti$\alpha$-tubulin antibody (Sigma-Aldrich, St. Louis, MO, USA) was used to confirm equivalent protein loading. Protein bands were quantified using AlphaView software, and the data were normalized to $\alpha$-tubulin.

\section{Statistical analysis}

The data has represented means of at least three independent experiments \pm SD. Statistical analysis was performed using either a t-test or one-way ANOVA, followed by the pairwise test or Bonferroni comparison to the control. The data was not used for statistical analysis, when etoposide was employed as a positive control. Data were log transformed if normality failed or unequal variability occurred. Differences were considered significant when the $P$ value was $<0.05$. Statistical analyses were conducted using SigmaPlot 11.0 software (Systat Software Inc., San Jose, CA, USA).

\section{Results}

\section{Effect of CB on caspase-3/7 activity}

Initial dose and time dependent experiments were used to determine the minimal CB amount that would initiate apoptosis. Dose determination results showed that $\mathrm{CB}$ treatment of HL-60 cells for $24 \mathrm{~h}$ led to significant increases in caspase-3/7 activity at both $25(P<0.05)$ and $50 \mu \mathrm{g} / \mathrm{ml}(P<0.001)$ (Fig. 1$)$. The incubation time study showed no significant changes in caspase $3 / 7$ activity in cells treated with $25 \mu \mathrm{g}$ of $\mathrm{CB}$ for $2 \mathrm{~h}$; however, significant increase in cell's activity was observed after incubation for 24 and $48 \mathrm{~h}(P<0.05)$. There was no significant difference between the two time points (Fig. 2). These results indicated that $24 \mathrm{~h}$ treatment of HL-60 cells with $25 \mu \mathrm{g} / \mathrm{ml} \mathrm{CB}$ could increase the activity of caspase $3 / 7$ and initiate an apoptosis pathway and consequently

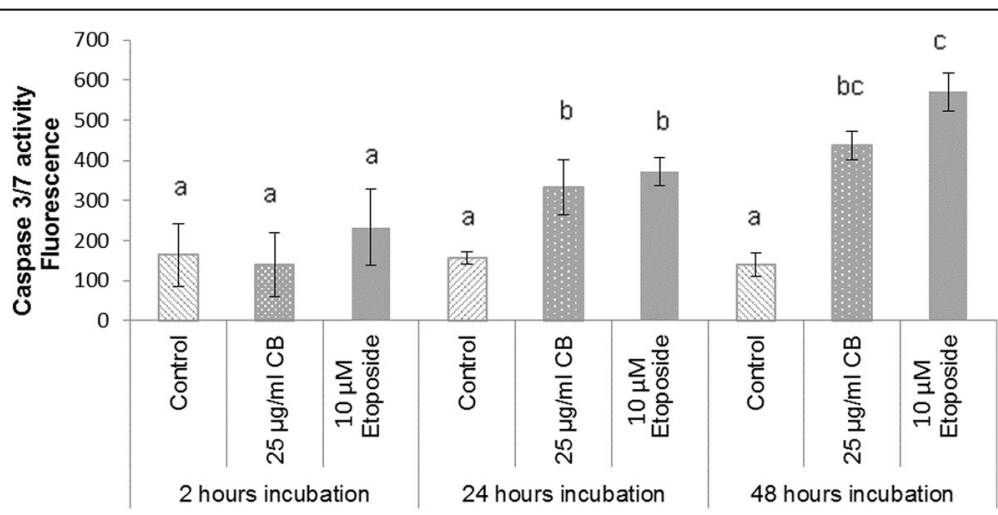

Fig. 2 Change in caspase-3/7 activity at different incubation time under the effect of $25 \mu \mathrm{g} / \mathrm{mL}$ CB and $10 \mu \mathrm{M}$ etoposide treatments. DMSO (0.1\%)-treated cells served as controls. The data represent the mean of three independent experiments \pm SD Statistical analysis were performed by one-way variance analysis (ANOVA). Different letters indicate significant differences among the means after Bonferroni's test $(P<0.05)$ 
these conditions were chosen to be applied for all further experiments.

\section{Effect of CB on caspase-8 and -9 concentrations}

A significant increase $(P<0.001)$ in the concentration of caspase-9 was observed through ELISA analysis of HL60 cells treated with $\mathrm{CB}$ for $24 \mathrm{~h}$ as shown in Fig. 3. However, caspase- 8 was not detected.

\section{Effect of $C B$ on mitochondrial outer membrane permeability (MOMP)}

Activation of caspase-9 is mostly depending on the release different proteins from the inner membrane space to the cytosol. Liberation of these proteins requires mitochondrial outer membrane permeabilization (MOMP).

24 h-CB-treated HL-60 cells showed stronger internal green fluorescence indicating an increase in MOMP, when compared to untreated cells. In addition, the fluorescence in cells treated with $\mathrm{CB}$ appeared as intense as observed in cells treated with the positive etoposide control (Fig. 4).

\section{Effect of CB on cytochrome $C$ and Smac levels}

Cytochrome $\mathrm{C}$ and Smac are one of the major proteins that will be found in the cytosol after MOMP stimulation. In this study, ELISA results detected rises in their cytosolic concentrations in HL-60 cells that treated with $\mathrm{CB}$ for $24 \mathrm{~h}$. Although the increasement detected was small in comparison to the untreated cells, the values were significantly $(P<0.001)$ different $($ Fig. 5$)$. Together, the results came to support the previous data that the change in MOMP led to the release of the pro-apoptotic

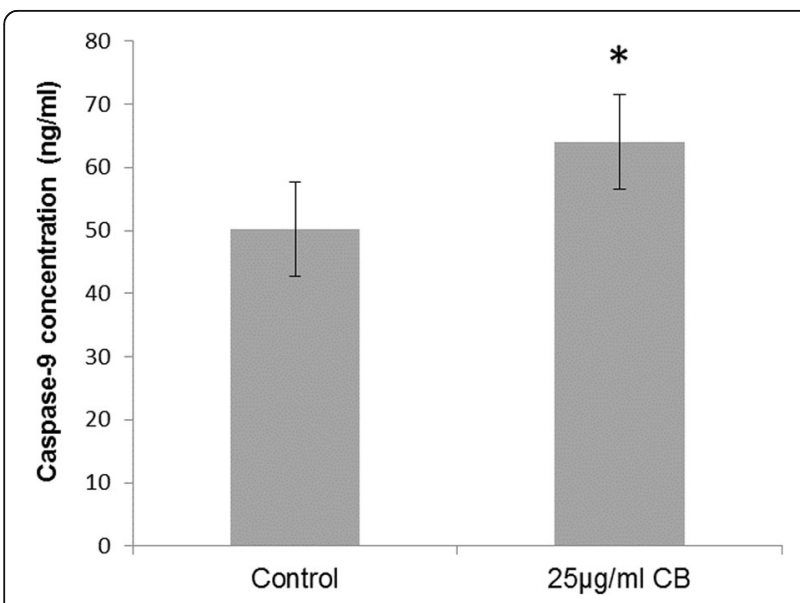

Fig. 3 Change in caspase-9 concentration. Cells were treated with $25 \mu \mathrm{g} / \mathrm{mL} \mathrm{CB}$ for $24 \mathrm{~h}$. Control or DMSO (0.1\%)-treated cells served as controls. Cell lysate was diluted two-fold with the sample diluent solution. Caspase-9 was measured by Caspase-9 Human ELISA Kit. The absorbance was taken at $450 \mathrm{~nm}$. The data represent the mean of three independent experiments \pm SD. Statistical analysis were performed by t-test ${ }^{*}, p<0.05$, compared with controls
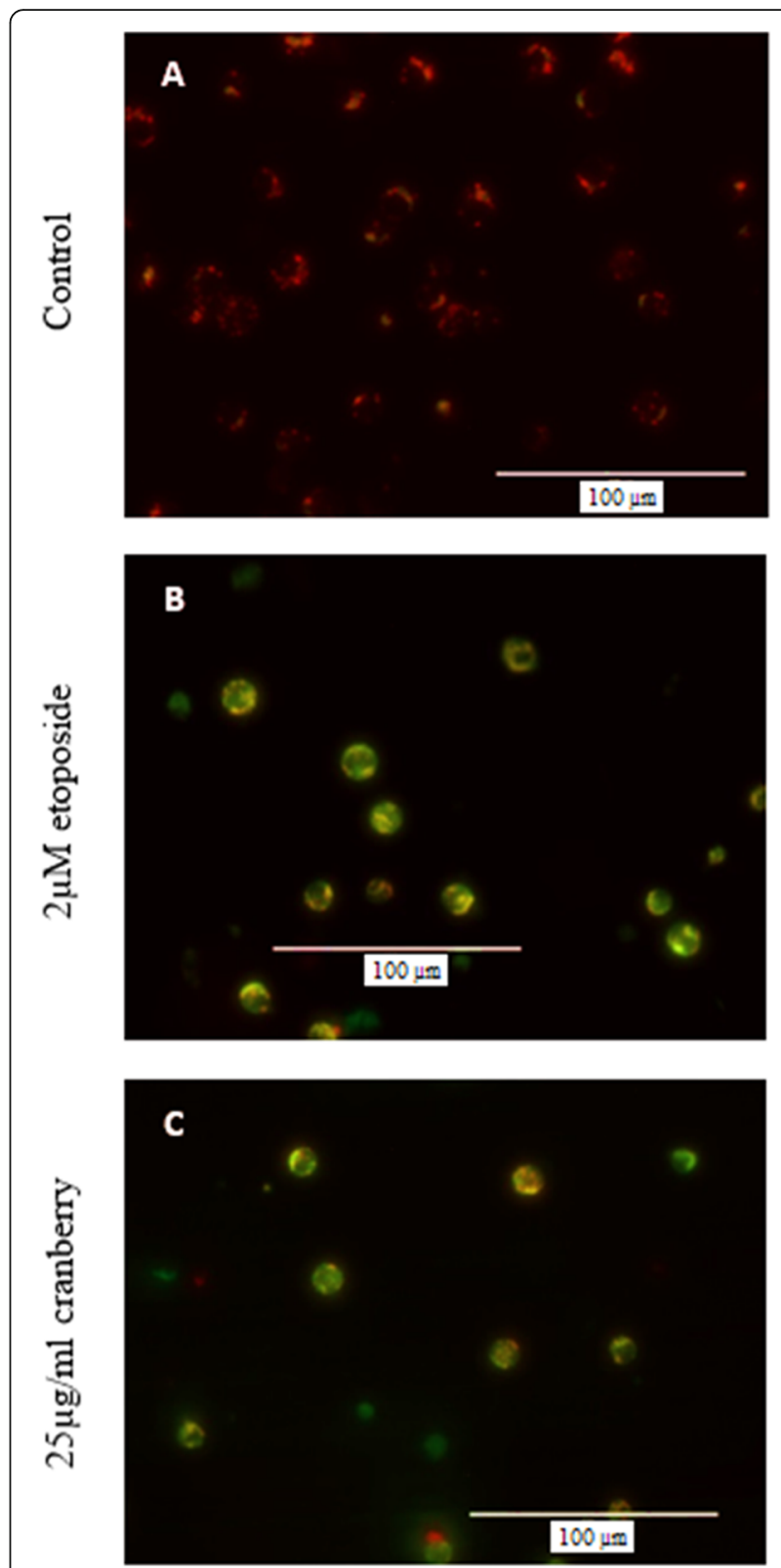

Fig. 4 Effect of CB on Mitochondrial Transmembrane Potential in $\mathrm{HL}-60$ cells. Cells were treated with $25 \mu \mathrm{g} / \mathrm{mL}$ CB for $24 \mathrm{~h}$. Control or DMSO (0.1\%)-treated cells served as controls. $2 \mu \mathrm{M}$ etoposide used as positive control. Cells were dyed with MitoCapture dye. Fluorescent signals detected by fluorescence microscopy

proteins; cytochrome $\mathrm{C}$ and Smac, from the inner membrane space of the mitochondria into the cytosol where they stimulate a cascade of caspase activation events leading to apoptosis.

Effect of CB on the expression of BCL-2 family proteins BCL-2 family proteins are known to play a major role in regulating MOMP and inhibiting/triggering intrinsic apoptotic pathways. The proteins subject to many post- 

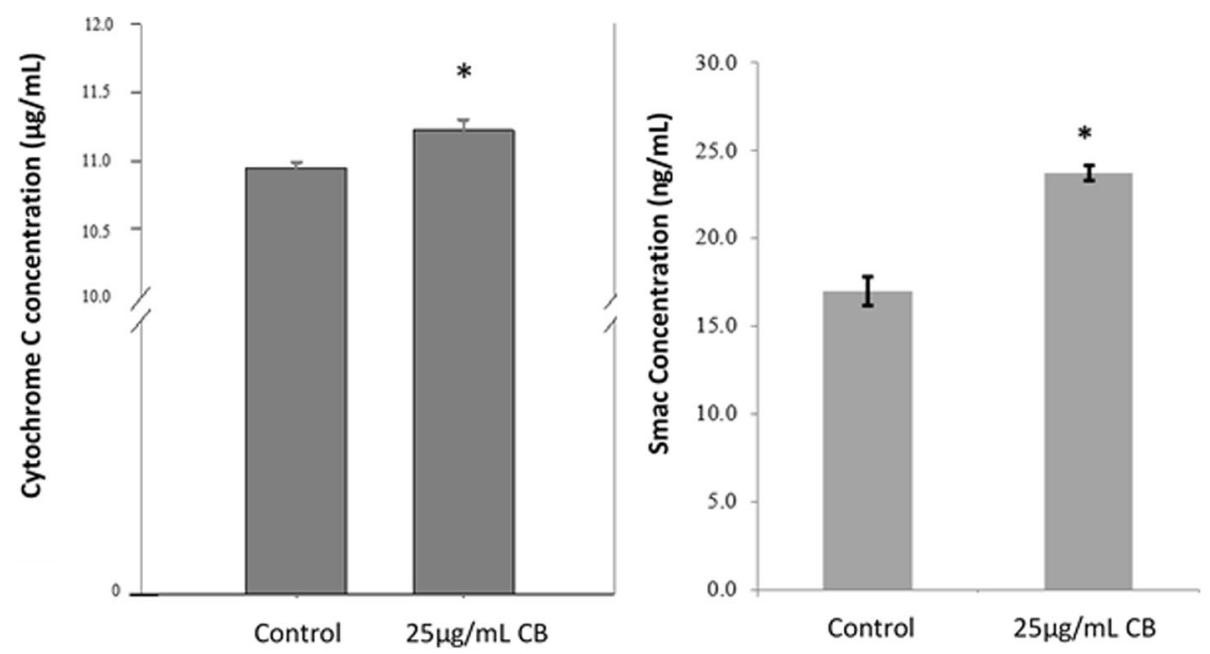

Fig. 5 Change in cytochrome C and Smac concentrations. Cells were treated with $25 \mu \mathrm{g} / \mathrm{mL}$ CB for $24 \mathrm{~h}$. Control or DMSO (0.1\%)-treated cells served as controls. The data represent the mean of three independent experiments \pm SD. Statistical analysis were performed by $t$ - test. *,$p<0.05$

translational modifications, specifically, phosphorylation. Therefore, total and phosphorylated form of some of BCL-2 family proteins were assessed. concerning relative protein expression levels of either total BCL-2 or its active form p-BCL-2 (Ser70) (Fig. 6).

\section{Pro-apoptotic proteins}

\section{Anti-apoptotic proteins}

Western blot detected no significant changes in cell lysates of HL-60 cells treated with $\mathrm{CB}$ for $24 \mathrm{~h}$
Since our results showed no change in $\mathrm{BCl} 2$ protein levels (both total and phosphorylated forms) we meant to focus on the role of the pro-apoptotic protein BAD as
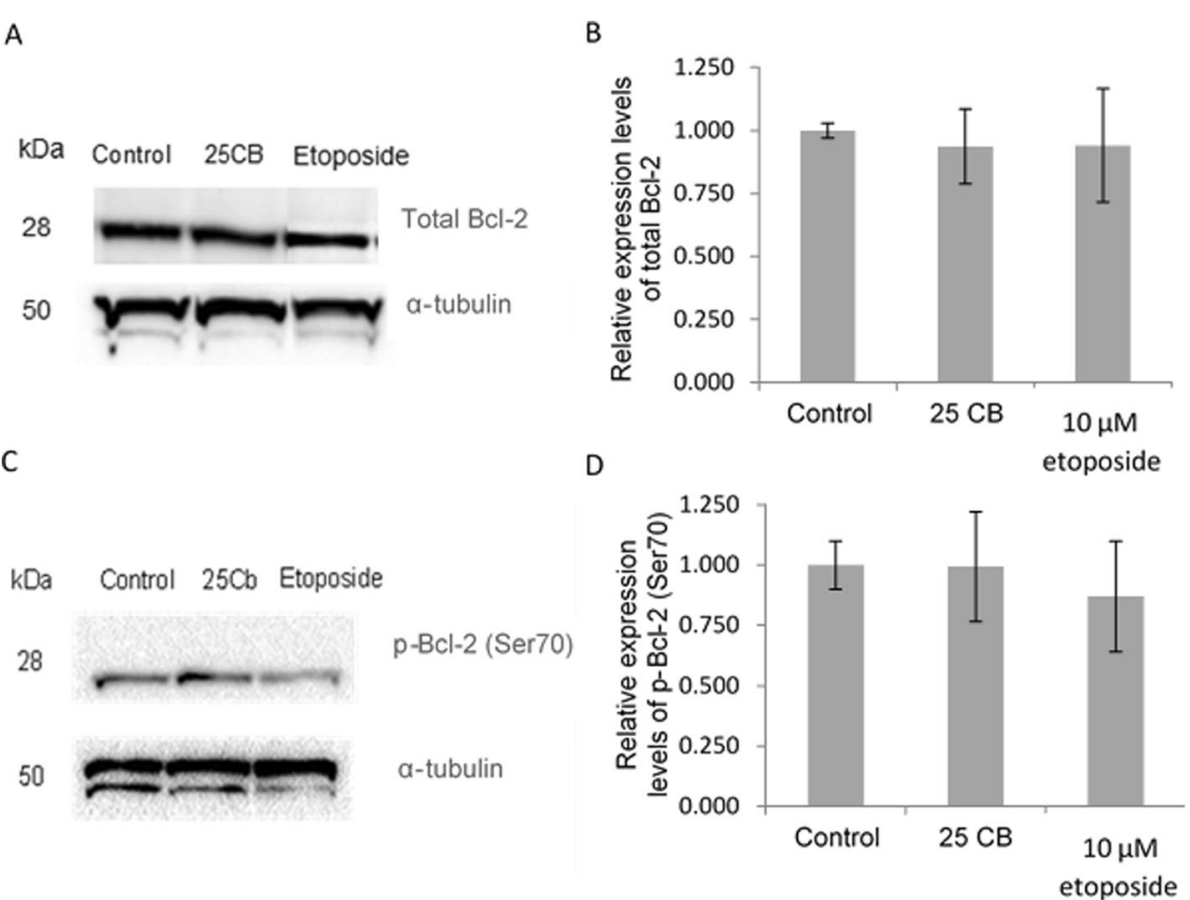

Fig. 6 Expression of the anti-apoptotic BCL-2 protein in $\mathrm{HL}-60$ cells treated with $\mathrm{CB}$. Representative immunoblots and relative expression of (a + b) total $\mathrm{BCL}-2$ and $(\mathbf{c}+\mathbf{d}) \mathrm{p}-\mathrm{BCL}-2$ (S70). Cells were treated for $24 \mathrm{~h}$ with $25 \mu \mathrm{g} / \mathrm{mL} \mathrm{CB}, 10 \mu \mathrm{M}$ etoposide or $0.1 \%$ DMSO. Total BCL-2 and p-BCL2(S70) expression were normalized to a-tubulin. Values are mean $\pm \mathrm{SD}, n=3$ 
it can bind to the BCL2 and help in releasing the proapoptotic proteins Bax and Bak, those can trigger apoptosis .

Western blot analysis of cell lysates from $24 \mathrm{~h}$ - CBtreated HL-60 cells found that the treatment did not affect levels of total BAD (Fig. 7), or its phosphorylated (inactive) forms at Ser112 (Fig. 8a,b) and ser-155 (Fig. 8e,f). However, CB treatment did have a significant impact $(P=0.022)$ on the dephosphorylation of BAD at Ser136.

\section{Effect of CB on AKT phosphorylation}

We investigated the involvement of Akt, which has been described as a downstream regulator of Bad.

ELISA analysis of HL-60 cells treated with CB for $24 \mathrm{~h}$ indicated a marked reduction of AKT phosphorylation at both Ser473 $(P=0.001)$ and Thr308 $(P=0.036)$ (Fig. 9a and b). This data revealed that $25 \mu \mathrm{g} / \mathrm{mL}$ cranberry treatment for $24 \mathrm{~h}$ can activate the pro-apoptotic Bad by inhibiting AKT phosphorylation at both Ser473 and Thr308 in HL-60.

\section{Discussion}

The present study has defined the mechanism by which CB triggers apoptosis in HL-60 cells that provided an important molecular framework for the apoptosis initiated by $\mathrm{CB}$. The lowest concentration of $\mathrm{CB}$ that initiates apoptosis has been determined. The preliminary results of the present study have showed that $24 \mathrm{~h}$ treatment of HL-60 cells with $25 \mu \mathrm{g} / \mathrm{ml}$ of CB activated two executioner caspases ( 3 and 7 ), and triggered apoptosis in those cells. The present study results are in agreement with few of the previous studies that $25 \mu \mathrm{g} / \mathrm{ml}$ of $\mathrm{CB}$ is effective in triggering apoptosis [18-20]. Cranberry juice contains PACs at a concentration of $418.8 \pm 75.3 \mu \mathrm{g} / \mathrm{ml}$; therefore, $25 \mu \mathrm{g} / \mathrm{ml}$ used in this study is appropriate within the PAC concentration of the juice itself [22].

In the intrinsic apoptotic pathway, caspase activation is associated with the permeability of the mitochondrial outer membrane (MOM) [23]. These results were similar to the present study stating that incubation of HL-60 cells with CB led to an increase in MOMP (Fig. 2). Few of the previous studies have also reported similar results stating that there is a significant impact of $\mathrm{CB}$ on MOMP [19, 24]. Caspase-mediated apoptosis can be induced through two major upstream pathways; intrinsic or mitochondrial, involving caspase-9 activation, or extrinsic or death receptor-related, which involves caspase- 8 activation $[3,21]$. The pathway used by apoptotic HL-60 cells after $24 \mathrm{~h}$ treatment with CB was determined by comparing the levels of caspases- 8 and -9 in treated and untreated cells. The results of present study have shown that treatment with $\mathrm{CB}$ significantly increased the level of caspase-9; however, caspase- 8 was not detectable in any of the samples.

Normally sequestered pro-apoptotic proteins, including cytochrome c and Smac, are released from the inter-membrane space into the cytosol when the MOM becomes permeable, which triggers a caspasedependent mitochondrial pathway [3, 14]. MacLean et al. [18] study reported significant induction in the cytosolic- cytochrome C level in human DU145 prostate cancer cells under the effect of the whole cranberry extract treatment. Moreover, a recent study conducted by Kresty et al. [25] showed that cranberry treatment led to a significant increase in levels of cytosolic cytochrome C. On the other hand, no report was found to evaluate the effectiveness of PAC rich cranberry extract in triggering the release of Smac from the mitochondrial intermembrane space into the
A

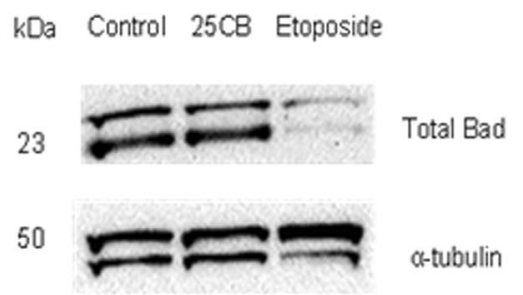

B

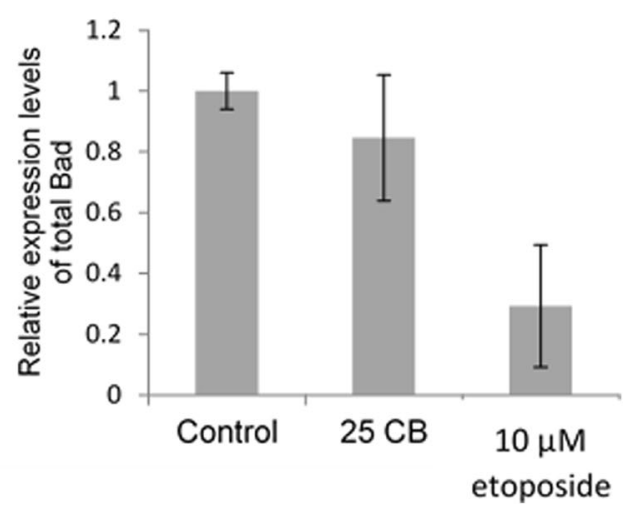

Fig. 7 Expression of the pro-apoptotic BAD protein in $\mathrm{HL}-60$ cells after treatment with CB. a Representative immunoblots and $\mathbf{b}$ relative expression of total BAD. HL-60 cells were treated with $25 \mu \mathrm{g} / \mathrm{mL} \mathrm{CB}, 10 \mu \mathrm{M}$ etoposide or $0.1 \%$ DMSO for $24 \mathrm{~h}$. Total BAD expression was normalized to a-tubulin. Values are mean $\pm S D, n=3$ 

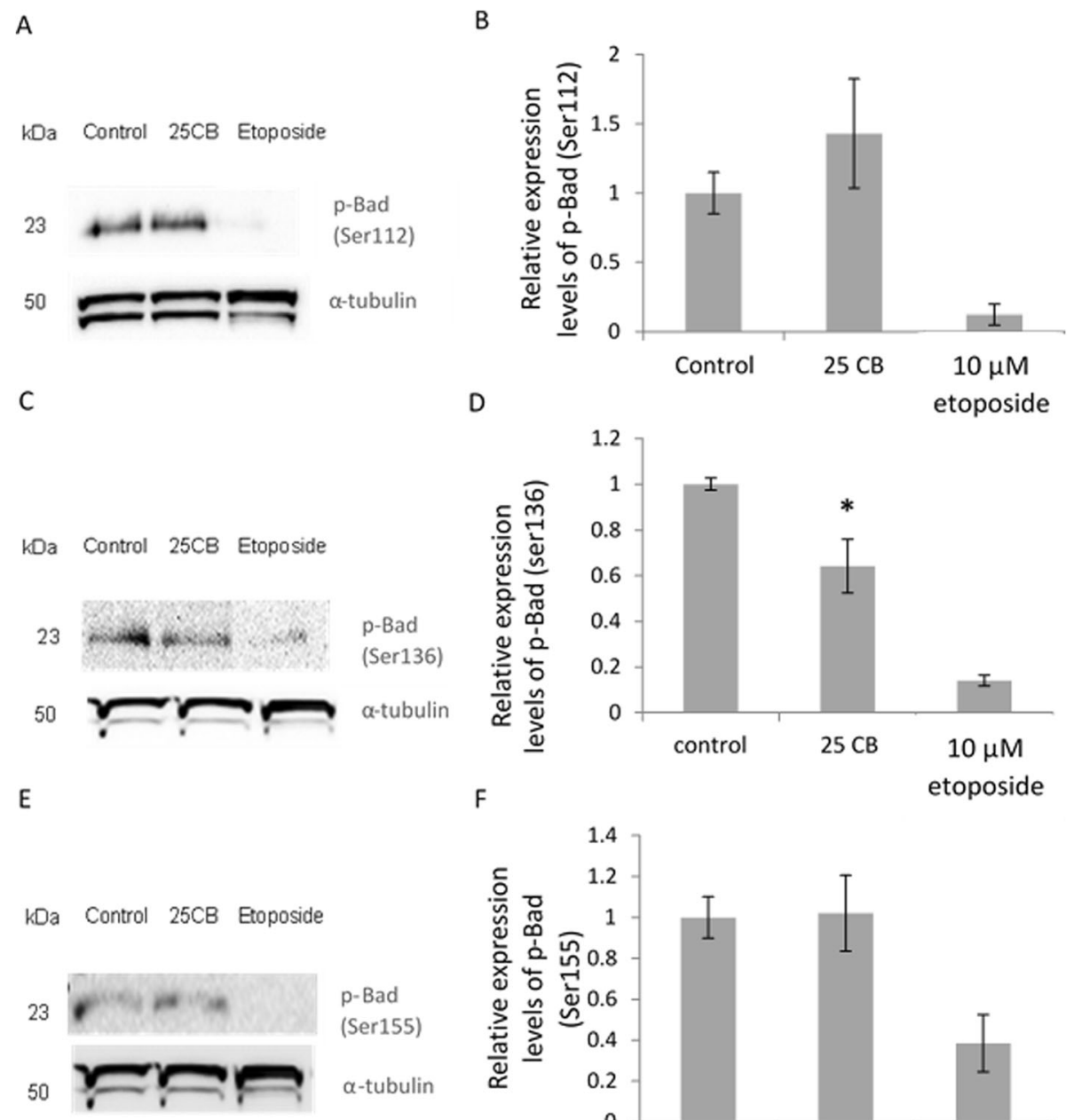

$\mathrm{F}$

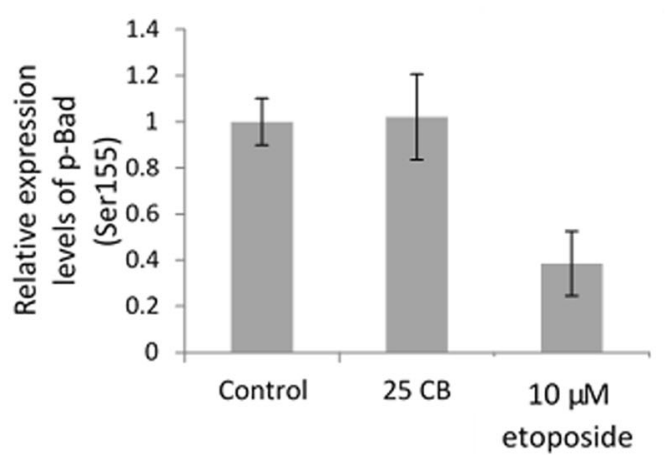

Fig. 8 Expression of p-Bad in HL-60 under the effect of CB treatment. a Representative immunoblots of p-Bad (ser112) and a-tubulin. b Relative expression level of p-Bad (ser112). c Representative immunoblots of p-Bad (ser136) a-tubulin. d Relative expression level of p-Bad (ser136). e Representative immunoblots p-Bad (ser155) a-tubulin. $\mathbf{f}$ Relative expression level of p-Bad (ser155). HL-60 Cells were treated with $0.1 \%$ DMSO (control), $25 \mu \mathrm{g} / \mathrm{mL}$ CBor $10 \mu \mathrm{M}$ etoposide (positive control) for $24 \mathrm{~h}$. Expressions of p-Bad were normalized to a-tubulin expression as an internal control. Data represent mean \pm SD from three independent experiments Statistical analysis were performed by one-way variance analysis (ANOVA) followed by Bonferroni's test. Statistical difference shown as $P<0.05\left[{ }^{*}\right]$

cytosol. However, the present study demonstrated that both cytochrome $\mathrm{C}$ and Smac were found in the cytosol of HL-60 cells treated with CB.

The balance between the anti-apoptotic and proapoptotic members of the BCL-2 family of proteins could be associated with an increase in MOMP. Moreover, the release of mitochondrial proteins is responsible for activating the caspase cascade of the intrinsic apoptotic pathway in the cytosol. BCL-2 family proteins are subjected to many post-translational modifications, specifically, phosphorylation. The functions of both BCL-2 and BAD proteins can be regulated by phosphorylation. The effect of cranberry on the level of expression of BCL-2 family proteins was evaluated by MacLean et al.
[18], which showed that cranberry treatment caused an increase in BAX and tBID protein levels, but had no effect on the expression of the BCL-2 protein. While, phosphorylation of BCL-2 at a single site (Ser70) is needed for maintaining its function in an anti-apoptotic manner [26].

In the present study, HL-60 cells were treated with $\mathrm{CB}$ and looked for changes in the phosphorylation status of $\mathrm{BAD}$, a pro-apoptotic protein, and $\mathrm{BCL}-2$, an antiapoptotic protein. The results showed a significant decrease in BAD phosphorylation at Ser136. However, none of the previous studies have evaluated whether $\mathrm{CB}$ interferes with post-translational phosphorylation of proteins within the BCL-2 family $[19,27,28]$. 
A

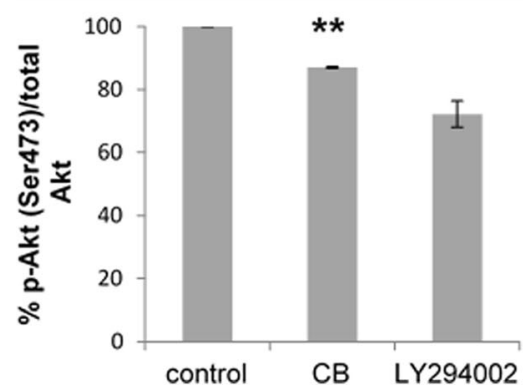

B

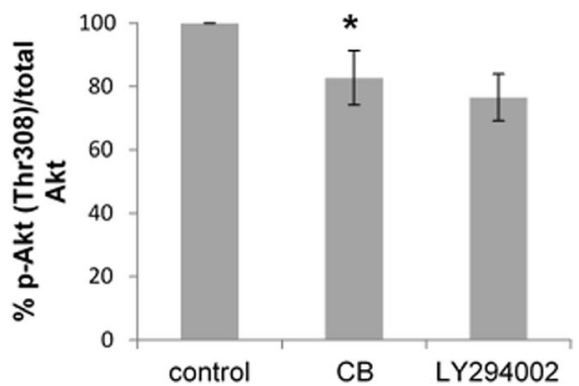

Fig. 9 Inhibition of Akt phosphorylation in CB- treated HL-60 cell. Cells were treated with 0.1\% DMSO (control), $25 \mu \mathrm{g} / \mathrm{mL}$ CB or $20 \mu \mathrm{M}$ PI3K inhibitor LY294002 (positive control) for $24 \mathrm{~h}$. cell lysates were assessed by ELISA for (a) p-Akt (Ser473) and (b) p-Akt (Thr308). Results are expressed as the percentage of $\mathrm{p}$-Akt after normalized for total Akt. Values are the mean \pm SD of 3 independent experiments. Statistical analysis were performed by one-way variance analysis (ANOVA) followed by Bonferroni's test $(p<0.05)$. Statistical difference shown as $\left.P<0.05{ }^{*}\right]$ and $P<0.001[* *]$

The present study has also investigated the involvement of AKT, a downstream regulator of BAD to elucidate the mechanism by which $\mathrm{CB}$ induced BAD activation. Previous literature has a model, in which active AKT phosphorylates BAD at Ser136 results in the dissociation of the BAD protein from BCL-2 [29, 30]. The protein is translocated into the cytosol resulting in subsequent binding/sequestation by 14-3-3 proteins leading to the inhibition of apoptosis and cell survival.

It has been hypothesized that $\mathrm{CB}$ was interfering with $\mathrm{BAD}$ phosphorylation by inhibiting $\mathrm{AKT}$ activity as the results indicated that $\mathrm{CB}$ reduced the phosphorylation of BAD at Ser136. Kvansakul \& Hinds [31] treated SKOV-3 ovarian cancer cells with $50 \mu \mathrm{g} / \mathrm{ml}$ cranberry-PAC extract and demonstrated that apoptosis was induced through the activation of both intrinsic and extrinsic pathways. The results showed a clear reduction of AKT activation and a significant reduction of both p-AKT (Ser473) and p-AKT (Thr308) levels demonstrating association between extrinsic and intrinsic pathways at this concentration. Similar results were found in the study conducted by Singh et al. [19] using neuroblastoma cell lines.

The present study has provided experimental results to define a cascade of events to explain how might $\mathrm{CB}$ interferes with specific proteins in HL-60 cells and triggers apoptosis via the intrinsic apoptotic pathway. Treatment with $\mathrm{CB}$ in these cells inhibited $\mathrm{AKT}$ activation resulting in $\mathrm{BAD}$ activation. Active $\mathrm{BAD}$ led to increase in the permeability of the MOM, which caused the release of the pro-apoptotic protein's cytochrome $\mathrm{C}$ and Smac into the cytosol. Presence of cytochrome $C$ in the cytosol will activate caspase-9. Consequently, the executioner caspase-3 will be activated. Cytosolic-Smac, on the other hand, will facilitate caspase activation through neutralizing the endogenous IAPs.
However, one limitation of the present study is the use of a single cell line (HL-60). Therefore, applying different cell lines in future research could contribute to validate the findings of the current study. In addition, assessing the effect of $\mathrm{CB}$ treatment on normal cells in comparison to cancerous cells is also needed.

\section{Conclusion}

The present study has explained the mechanism initiated by cranberry that triggers apoptosis in HL-60 cells. The results demonstrated that cranberry inhibited AKT activity in HL-60 cells, accompanied by a significant reduction of p-AKT (Ser473) and p-AKT (Thr308). The present study has suggested that link between cranberryinduced AKT inhibition and BAD activation, which results in the initiation of intrinsic apoptosis in HL-60 cells. It has provided novel insight into the sequence of events to describe the mechanism by which intrinsic apoptosis is triggered by CB in HL-60 cells.

\section{Abbreviations}

AKT: Protein Kinase B; BAD: BCL-2-associated death promoter; BAX: BCL2Associated X Protein; BCL-2: B-cell lymphoma-2; CB: Cranberry Extract; $\mathrm{CO}_{2}$ : Carbon Dioxide; DMSO: Dimethyl Sulfoxide; ELISA: Enzyme-Linked Immunosorbent Assay; HRP: Horseradish Peroxidase; MOM: Mitochondrial Outer Membrane; MOMP: Mitochondrial Outer Membrane Permeability; PAC: Proanthocyanidins; PBS: Phosphate Buffered Saline; RIPA buffer: Radioimmunoprecipitation Assay Buffer; SDS-PAGE: Sodium Dodecyl Sulfate-Polyacrylamide Gel Electrophoresis; SMAC: Second MitochondriaDerived Activator of Caspases; TBID: Truncated BH3 Interacting Domain Death Agonist; TBST: Tris Buffered Saline with Tween

\section{Acknowledgments}

The authors would like to thank Dr. Cheryl Ann Rowe for editing the manuscript.

\section{Authors' contributions}

R.M designed the study, worked in all stages of lab work and data analysis and wrote the manuscript. S. P was responsible for supervising the project, contributed to interpretation of the results and reviewed the draft. All authors have read and approved the manuscript and ensure that this is the case. 


\section{Funding}

This research did not receive any specific grant from funding agencies in the public, commercial, or not-for-profit sectors.

\section{Availability of data and materials}

The datasets used and analyzed during the current study are available from the corresponding author on reasonable request.

\section{Ethics approval and consent to participate}

Not applicable

\section{Consent for publication}

Not applicable

\section{Competing interests}

The authors declare that they have no competing interests.

\section{Author details}

'Department of Biochemistry, King Abdul Aziz University, Jeddah, Saud Arabia. ${ }^{2}$ Food Science and Human Nutrition Department, University of Florida, Gainesville, FL 32611, USA.

Received: 21 March 2019 Accepted: 26 February 2020

Published online: 06 March 2020

\section{References}

1. Penberthy KK, Ravichandran KS. Apoptotic cell recognition receptors and scavenger receptors. Immunol Rev. 2016;269:44-59. https://doi.org/10.1111/ imr.12376.

2. Shi YG. Activation of initiator caspases: history, hypotheses, and perspectives. J Cancer Mol. 2005;1:9-18.

3. Elmore S. Apoptosis: a review of programmed cell death. Toxicol Pathol. 2007;35:495-516. https://doi.org/10.1080/01926230701320337.

4. Riedl SJ, Shi Y. Molecular mechanisms of caspase regulation during apoptosis. Nat Rev Mol Cell Biol. 2004;5:897. https://doi.org/10.1038/ nrm1496.

5. Kopeina GS, Prokhorova EA, Lavrik IN, Zhivotovsky B. Alterations in the nucleocytoplasmic transport in apoptosis: Caspases lead the way. Cell Prolif. 2018;51:e12467. https://doi.org/10.1111/cpr.12467.

6. Fuentes-Prior $P$, Salvesen GS. The protein structures that shape caspase activity, specificity, activation and inhibition. Biochem J. 2004;384:201-32. https://doi.org/10.1042/bj20041142

7. Lüthi AU, Martin SJ. The CASBAH: a searchable database of caspase substrates. Cell Death Differ. 2007;14:641. https://doi.org/10.1038/sj.cdd. 4402103.

8. Kischkel FC, Lawrence DA, Chuntharapai A, Schow P, Kim KJ, Ashkenazi A. Apo2L/TRAlL-dependent recruitment of endogenous FADD and caspase-8 to death receptors 4 and 5. Immunity. 2000;12:611-20. https://doi.org/10. 1016/s1074-7613(00)80212-5.

9. Man SM, Kanneganti TD. Converging roles of caspases in inflammasome activation, cell death and innate immunity. Nat Rev Immunol. 2016;16:7. https://doi.org/10.1038/nri.2015.7.

10. Ashkenazi A. Targeting the extrinsic apoptosis pathway in cancer. Cytokine Growth Factor Rev. 2008;19:325-31. https://doi.org/10.1016/j.cytogfr.2008.04. 001

11. Su Z, Yang Z, Xu Y, Chen Y, Yu Q. Apoptosis, autophagy, necroptosis, and cancer metastasis. Mol Cancer. 2015;14:48. https://doi.org/10.1186/s12943015-0321-5.

12. Shi Y. Caspase activation, inhibition, and reactivation: a mechanistic view. Protein Sci. 2004;13:1979-87. https://doi.org/10.1110/ps.04789804.

13. Tait SW, Green DR. Mitochondria and cell death: outer membrane permeabilization and beyond. Nat Rev Mol Cell Biol. 2010;11:621. https://doi. org/10.1038/nrm2952

14. Fulda S, Debatin KM. Extrinsic versus intrinsic apoptosis pathways in anticancer chemotherapy. Oncogene. 2006;25:4798. https://doi.org/10.1038/ sj.onc. 1209608

15. Maki KC, Kaspar KL, Khoo C, Derrig LH, Schild AL, Gupta K. Consumption of a cranberry juice beverage lowered the number of clinical urinary tract infection episodes in women with a recent history of urinary tract infection. Am J Clin Nutr. 2016;103:1434-42.
16. Neto CC, Vinson JA. Cranberry. In: Herbal Medicine: Biomolecular and Clinical Aspects. 2nd edition. ProQuest LLC. Ann Arbor: CRC Press/Taylor \& Francis; 2011. p. 2011.

17. Bomser J, Madhavi DL, Singletary K, Smith MA. In vitro anticancer activity of fruit extracts from Vaccinium species. Planta Med. 1996;62:212-6. https://doi. org/10.1055/s-2006-957862.

18. MacLean MA, Scott BE, Deziel BA, Nunnelley MC, Liberty AM, Gottschall-Pass KT, Neto CC, Hurta RA. North American cranberry (Vaccinium macrocarpon) stimulates apoptotic pathways in DU145 human prostate cancer cells in vitro. Nutr Cancer. 2011;63:109-20. https://doi.org/10.1080/01635581.2010. 516876

19. Singh AP, Lange TS, Kim KK, Brard L, Horan T, Moore RG, Vorsa N, Singh RK. Purified cranberry proanthocyanidines (PAC-1A) cause pro-apoptotic signaling, ROS generation, cyclophosphamide retention and cytotoxicity in high-risk neuroblastoma cells. Int J Oncol. 2012;40:99-108. https://doi.org/ 10.3892/ijo.2011.1225.

20. Weh K, Clarke J, Kresty L. Cranberries and cancer: an update of preclinical studies evaluating the cancer inhibitory potential of cranberry and cranberry derived constituents. Antioxidants. 2016;5:27. https://doi.org/10.3390/ antiox5030027.

21. Eum KH, Lee M. Crosstalk between autophagy and apoptosis in the regulation of paclitaxel-induced cell death in v-ha-ras-transformed fibroblasts. Mol Cell Biochem. 2011;348:61-8. https://doi.org/10.1007/s11010 010-0638-8.

22. Gu L, Kelm MA, Hammerstone JF, Beecher G, Holden J, Haytowitz D, Gebhardt S, Prior RL. Concentrations of proanthocyanidins in common foods and estimations of normal consumption. J Nutr. 2004;134:613-7. https://doi.org/10.1093/jn/134.3.613.

23. Xiao D, He H, Huang W, Oo TL, Wang A, He LF. Analysis of mitochondrial markers of programmed cell death. In: Plant programmed cell death. New York: Humana Press; 2018. p. 65-71.

24. Kim KK, Singh AP, Singh RK, DeMartino A, Brard L, Vorsa N, Lange TS, Moore RG. Anti-angiogenic activity of cranberry proanthocyanidins and cytotoxic properties in ovarian cancer cells. Int J Oncol. 2012;40:227-35. https://doi. org/10.3892/ijo.2011.1198.

25. Kresty LA, Weh KM, Zeyzus-Johns B, Perez LN, Howell AB. Cranberry proanthocyanidins inhibit esophageal adenocarcinoma in vitro and in vivo through pleiotropic cell death induction and PI3K/AKT/mTOR inactivation. Oncotarget. 2015;6:33438. https://doi.org/10.18632/oncotarget.5586.

26. Ruvolo PP, Deng X, May WS. Phosphorylation of $\mathrm{BCl} 2$ and regulation of apoptosis. Leukemia. 2001;15:515. https://doi.org/10.1038/sj.leu.2402090.

27. Kresty LA, Howell AB, Baird M. Cranberry proanthocyanidins mediate growth arrest of lung cancer cells through modulation of gene expression and rapid induction of apoptosis. Molecules. 2011;16:2375-90. https://doi.org/10. 3390/molecules16032375.

28. Mansouri RA. Cranberry extract initiates intrinsic apoptosis in HL-60 cells by increasing Bad activity through the inhibition of Akt phosphorylation. Doctoral dissertation, University of Florida; 2016

29. Datta SR, Dudek H, Tao X, Masters S, Fu H, Gotoh Y, Greenberg ME. Akt phosphorylation of BAD couples survival signals to the cell-intrinsic death machinery. Cell. 1997;91:231-41. https://doi.org/10.1016/s00928674(00)80405-5.

30. del Peso L, González-García M, Page C, Herrera R, Nunez G. Interleukin-3induced phosphorylation of BAD through the protein kinase Akt. Science. 1997:278:687-9. https://doi.org/10.1126/science.278.5338.687.

31. Kvansakul M, Hinds MG. Structural biology of the BCl-2 family and its mimicry by viral proteins. Cell Death Dis. 2013:4:e909. https://doi.org/10. 1038/cddis.2013.436

\section{Publisher's Note}

Springer Nature remains neutral with regard to jurisdictional claims in published maps and institutional affiliations. 